\title{
Correlation between blood and lymphatic microvascular density and cell proliferation in mouth floor and tongue squamous cell carcinoma
}

\author{
Fernanda Bertini ${ }^{a}$, Renata Falchete do Prado ${ }^{a}$,* , Aline Júnia de Oliveira ${ }^{a}$, \\ Tábata de Melo Tera ${ }^{\mathrm{a}}$, Luiz Eduardo Blumer Rosa ${ }^{\mathrm{a}}$, Julia Carvalho Seabra ${ }^{\mathrm{b}}$, \\ Yasmin Rodarte Carvalho ${ }^{\mathrm{a}}$ \\ a Department of Bioscience and Oral Diagnosis, Institute of Science and Technology, Univ Estadual Paulista (UNESP), Av. Engenheiro Francisco José Longo, \\ 777, São José dos Campos, 12245-000 SP, Brazil \\ ${ }^{\mathrm{b}}$ Faculdade de Medicina, Universidade de Santo Amaro - UNISA, Rua Professor Enéas de Siqueira Neto, 340, São Paulo, 04829-300 SP, Brazil
}

\section{A R T I C L E I N F O}

\section{Article history:}

Received 6 May 2016

Received in revised form 20 May 2016

Accepted 30 May 2016

Available online 20 June 2016

\section{Keywords:}

Oral cancer

Ki-67

D2-40

CD105

Squamous cell cancer

\begin{abstract}
A B S T R A C T
Objective: Despite the advances in medicine, the oral squamous cell carcinomas still have high incidence and are very important to study topics such as their lymphatic and microvessel density. This research assessed the correlation between histological grading, formation of new lymphatic and blood vessels and cell proliferation in squamous cell carcinomas (SCC).

Methods: Twenty-nine oral floor SCC and 30 tongue cases were assessed for their clinical characteristics and histological grading of malignancy.

Results: The presence of VEGF (vascular endothelial growth factor VG1), VEGF-C (vascular endothelial growth factor-C), CD105, to determine blood microvascular (MVD), and D2-40 to determine lymphatic density (LMD) was investigated using immunohistochemistry. Histological grading revealed that $73.3 \%$ of tongue and $96.67 \%$ of floor cases were classified as highly aggressive. Cell proliferation was greater on the floor; however, no significant difference was observed. Most carcinomas were VEGF negative (tongue $63.3 \%$ and floor $70.0 \%$ ) and VEGF-C positive (tongue 73.3\% and floor 79.3\%). LMD was considerably greater on the tongue. High MVD values occurred in cases with greater cell proliferation. No relationship was determined between the growth factors VEGF and VEGF-C and MVD and LMD, respectively.

Conclusion: Floor of mouth SCC cases was morphologically more aggressive than tongue cases; however, in tongue carcinomas a greater quantity of lymphatic vessels could represent potential ways for locoregional cell dissemination of the neoplastic cells, independent of histological grading. Blood vascularization presented correlation with cell proliferation in intraoral squamous cell carcinoma and could be useful in the prognostic assessment of this neoplasm.

@ 2016 Asian AOMS, ASOMP, JSOP, JSOMS, JSOM, and JAMI. Published by Elsevier Ltd. All rights reserved.
\end{abstract}

\section{Introduction}

Oral squamous cell carcinoma (SCC) representing $3 \%$ of all malignant tumors is considered the 6th most frequent cancer [1], with regional variations in incidence and mortality rates [2]. These neoplasms are mostly diagnosed at an advanced stage and are therefore

\footnotetext{
论 Asian AOMS: Asian Association of Oral and Maxillofacial Surgeons; ASOMP: Asian Society of Oral and Maxillofacial Pathology; JSOP: Japanese Society of Oral Pathology; JSOMS: Japanese Society of Oral and Maxillofacial Surgeons; JSOM: Japanese Society of Oral Medicine; JAMI: Japanese Academy of Maxillofacial Implants.

* Corresponding author at: Faculdade de Odontologia de São José dos Campos UNESP, Departamento de Biociências e Diagnóstico Bucal, Av. Francisco José Longo, 777, São José dos Campos, 12245-000 São Paulo, Brazil. Tel.: +55 211239479357; fax: +55 211239479010 .

E-mail address: renatafalchete@hotmail.com (R.F. do Prado).
}

regarded as a serious problem by local health authorities [3,4]. With the exception of cases involving the lips, the most common sites for mouth cancer are the tongue, mouth floor, and soft palate with most cases occurring in men over 5-6th decades of life [5]. The same places were also preferable sites for oropharynx SCC [6]. Persistent mucosal erythroplasia rather than leukoplakia is the earliest visual sign of oral and oropharyngeal carcinoma. These lesions should not be regarded merely as precancerous changes. The evidence indicates that these lesions in high-risk sites should be considered to be invasive carcinoma or carcinoma in situ unless proven otherwise by biopsy [6].

Despite the advances in medicine, the prognosis of these types of cancer remains unfavorable considering a survival rate of $56 \%$ over 5 years $[7,8]$. Prognosis depends on numerous factors, including early detection and histological grading [9]. 
In order to define a more precise estimate regarding the biological behavior of SCC, several histological grading systems have been developed [5,10-12]. However none of them alone are able to predict neoplastic behavior. Thus, the search for prognostic markers is very important, and can contribute to determine treatment and estimate a patient's survival time.

A correlation often exists between the proliferation rate of neoplastic cells and the biological behavior of tumors [13,14]. Ki-67 antibodies are commonly evaluated to detect and quantify cell proliferation $[15,16]$.

Angiogenesis is fundamental for tumor development because vessels carry nutrient to neoplastic cells during the division process, resulting in favorable conditions for tumor cells. The progression process of a normal cell to malignancy involves numerous mechanisms; one of which is the capacity to stimulate angiogenesis through the increased secretion of vessel-inductors and suppression of inhibitors [17]. Additionally, head and neck cancer is known to result in locoregional metastasis via lymphatic network, so, lymphangiogenesis is also considered an important process for tumor metastasis spread [18-21].

Owing to the importance of angiogenesis in the growth of neoplasm and lymphangiogenesis in lymph node metastasis, several studies have assessed these phenomena as prognostic factors for neoplasms [22,23].

Considering that cell proliferation has been proposed as a prognostic factor for squamous cell carcinoma, this study assessed the correlation between endothelial growth factors and proliferation, also exploring the relationship between neoformation of blood and lymphatic vessels and histological grading of malignancy.

\section{Material and methods}

This study followed the Ethical Principles for Research on Humans and was approved by the Local Research Ethics Committee, under protocol no. 093/2007-PH/CEP.

Among the 59 cases of intraoral SCC selected, 30 of them originated from the anterior two thirds of tongue and 29 from floor of the mouth. The clinical data (skin color, gender and age); sections stained with hematoxylin-eosin (H-E) and paraffin embedded blocks were obtained from the archives of the Oral Pathology Laboratory.

\subsection{Histological grading}

To evaluate malignancy, the histological grading proposed by Bryne et al. [12] was used. This is based on analysis of morphological features presented by the cells and their relationship with connective tissue in the region of tumor invasive front; i.e., the most invasive portion visualized by the microscopic cut. The degree of keratinization, nuclear polymorphism, number of mitoses per field, invasion pattern and the leukocyte infiltration were analyzed, each with a score varying from 1 to 4 . The analyses were performed by two examiners.

\subsection{Immunohistochemical analysis}

For cell proliferation analysis, an immunohistochemical reaction was performed using the LSAB system (peroxidase immunostaining method, Dako Corp., Carpinteria, USA) using an antibody against Ki-67. Vascular endothelial (VEGF-VG1) and endothelial lymphatic growth factors (VEGF-C) were also assessed. The blood and lymphatic microvascular density were analyzed by endothelial antigens marking CD105 and D2-40, respectively. The incubation period for all antibodies was $1 \mathrm{~h}$. Details concerning the immunohistochemical techniques and antibodies used are listed in Table 1. Positive controls were obtained according manufactures instructions. For Ki-67, it was used a case of SCC, for D2-40 and VEGF-C it was used a case of lymphangioma, for CD-105 a lymph node and for VEGF a case of lymphoid hyperplasia. As negative controls, reactions were carried out in the same way of samples, except for the incubation using only antibody diluent, without primary antibody.

For analysis of Ki-67 expression (proliferation index), microscopic fields considered to have the greatest density [hot-spots] were identified using $100 \times$ magnification. Positive staining for $\mathrm{Ki}-67$ was verified in nuclei of neoplastic epithelial cells. The proliferation index is the percentage of positive cells of a total of 1000 tumor cells, counted by a single examiner in approximately 5 fields of each neoplasm, under a $400 \times$ magnification.

The expression of VEGF and VEGF-C was assessed by an examiner using a semiquantitative method of scores, based on the sum of proportion and intensity of tumor cells with positive marking, as previously proposed by Soini et al. [24]. For each selected field, the positive cell percentage was assessed and classified in five scores: $\mathbf{0}=$ absence of positive tumor cells; $\mathbf{1}=$ less than $25 \%$ of positive tumor cells; $\mathbf{2}=26-50 \%$ of positive tumor cells; $\mathbf{3}=51-75 \%$ of positive tumor cells and $\mathbf{4}=$ more than $75 \%$ of positive tumor cells. The intensity was classified by the following scores: $\mathbf{0}=$ absence of marking; $\mathbf{1}$ = weak marking; $\mathbf{2}$ = moderate marking; $\mathbf{3}=$ strong marking and $\mathbf{4}=$ intense marking. The percentage and intensity scores were summed resulting in the following: $\mathbf{0}$ (sum zero $)$ absence of marking; $\mathbf{1}($ sum from 1 to 4$)=$ weak marking and $2($ sum $5-8)=$ strong marking.

The blood and lymphatic vessel counts were performed by one researcher, in accordance with Maeda et al. [25]. Any cell or endothelial cell group positively stained by markers CD105 and D240 , separated from the adjacent micro vessels, from tumor cells and from other elements of connective tissue was considered a unitary vessel, together with vessels containing lumen. Branched structures were counted as unitary vessels. Hot spot regions were selected using $200 \times$ of magnification. In these regions, the vessels were manually counted in 5 fields at $400 \times$ magnification and the result was expressed by the average number of vessels in each histological cut.

Table 1

Details of the primary antibodies used.

\begin{tabular}{|c|c|c|c|c|}
\hline Antigen specificity & Clone & Dilution & $\begin{array}{l}\text { Visualization } \\
\text { system }\end{array}$ & $\begin{array}{l}\text { Pre-treatment } \\
\text { Antigen recovery }\end{array}$ \\
\hline CD105 & SN6h ${ }^{\mathrm{a}}$ & $1: 50$ & Histofine ${ }^{c}$ & Proteinase $\mathrm{K}^{\mathrm{a}}$ (room temperature), $6 \mathrm{~min}$ \\
\hline $\mathrm{D} 2-40$ & M3619 & $1: 100$ & Histofine & Double boiler $\left(95^{\circ} \mathrm{C}\right), 45 \mathrm{~min}$ - Citrate \\
\hline Ki-67 & MIB-1 ${ }^{\text {a }}$ & $1: 100$ & $\mathrm{LSAB}^{\mathrm{a}}$ & Double boiler $\left(95^{\circ} \mathrm{C}\right), 45 \mathrm{~min}$ - Citrate \\
\hline VEGF & $\mathrm{VG} 1^{\mathrm{a}}$ & $1: 50$ & Histofine & $\begin{array}{l}\text { Double boiler }\left(95^{\circ} \mathrm{C}\right), 45 \mathrm{~min} \text { - Tris EDTA Target } \\
\text { Retrieval Solution }^{\mathrm{a}}\end{array}$ \\
\hline VEGF-C & $\mathrm{H}-190^{\mathrm{b}}$ & $1: 20$ & Histofine & Double boiler $\left(95^{\circ} \mathrm{C}\right), 45 \mathrm{~min}$ - Citrate \\
\hline
\end{tabular}

\footnotetext{
a Dako Corporation, Glostrup, Denmark.

b Santa Cruz Biotechnology, CA, USA.

c Nichirei Biosciences Inc.
} 


\subsection{Statistical analysis}

Statistical analysis was performed using the Minitab statistical program version 16.0. The results were submitted to descriptive and inferential statistical analysis with the application of the Pearson Correlation Coefficient, Student test and the Fisher Exact test, with $5 \%$ of significance in all tests. The Kappa test was used to assess the agreement between the examiners regarding the histological grading of malignancy.

\section{Results}

Among the cases assessed, there was a prevalence of males, corresponding to $76.7 \%$ of all cases. White people showed higher prevalence, corresponding to $71.7 \%$ of cases. Patient mean age was 59.2 years. For floor and tongue cases, it was respectively 57.5 and 61.0 years.

The Kappa test for histological grading yielded a result of 0.63 , confirming good agreement. The results of one examiner were used.

When analyzing the final malignancy grading scores, $73.3 \%$ of tongue cases and $96.7 \%$ floor cases were highly aggressive. Analysis by the Fisher Exact test $(p=0.026)$ revealed that the proportions between the sites differed from one another.

Table 2 shows the immunohistochemical results of SCC of the tongue and mouth floor. The staining pattern for Ki-67 presented wide variation among cases. Although the mean was greater in the floor of mouth samples, proportion testing and comparison of the values obtained confirmed that there was no statistically significant difference between tumor sites ( $p=0.899)$.

VEGF and VEGF-C were detected in the cytoplasm, membrane and occasionally in the nuclei of tumor cells and mucosa epithelium. When an intense staining was observed, it was located in tumor cells at the neoplasm invasion front. VEGF and VEGF-C were rarely located in the vascular endothelium.

Labeling for VEGF occurred in a minority of cases $36.7 \%$ in tongue and $30.0 \%$ in oral floor cases), with no significant difference between regions ( $p=0.583$ ). Positive VEGF-C staining was observed in most cases (73.3\% in tongue and $79.3 \%$ in oral floor), with no significant difference $(p=0.588)$.

Figs. 1 and 2 illustrate D2-40 and CD105 immunostaining, respectively. MVD was not different between cases of tongue and mouth floor $(p=0.108)$, while LMD demonstrated greater D2-40 expression and consequently higher LMD in cases that affected the tongue $(p=0.001)$ comparing to floor.

In tongue, Student $t$ test determined greater LMD than MVD values $(p=0.001)$. In the floor of mouth cases, no significant differences were observed between blood and lymphatic microvascular density.

Values for correlation of blood microvascular (CD105) and cell proliferation (Ki-67) and correlation of lymphatic density (D2-40) and cell proliferation (Ki-67) were analyzed using Pearson's correlation test. The following values $r=0.328, p=0.011$ and $r=0.072$, $p=0.590$ were respectively obtained. Greater blood microvascular density occurred together with greater Ki-67 expression, though no

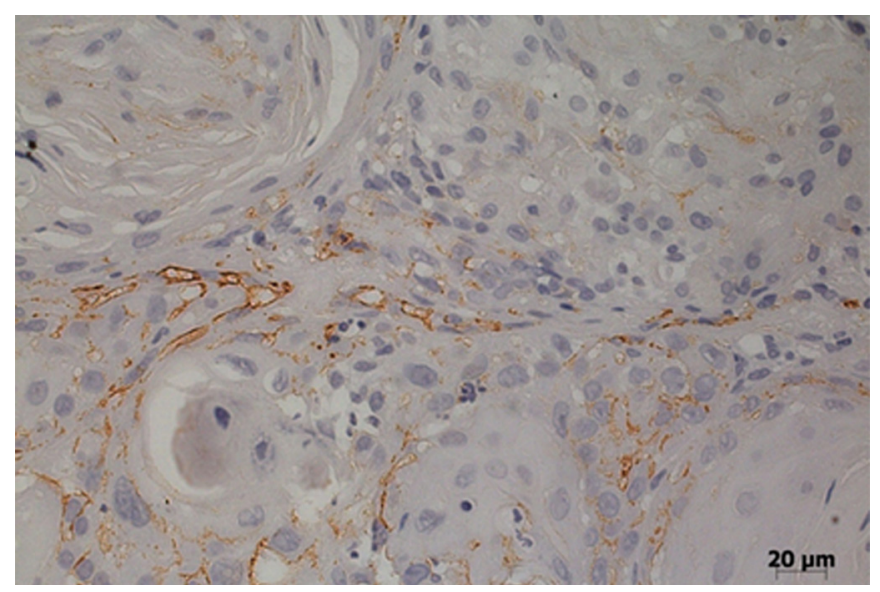

Fig. 1. D2-40 labeling lymphatic vessels of tongue squamous cell carcinoma (imunohistochemistry).

significant correlation was obtained between lymphatic microvascular density and cell proliferation.

Analyzing the data of VEGF expression and MVD, greater VEGF was demonstrated in cases with smallest MVD (Table 3).

Regarding the relation between VEGF-C and LMD, the mean LMD was greater in cases with strong VEGF-C labeling; however, there were no significant differences between the LMD means (Table 4).

Evaluation of MVD and LMD regarding the histological grading of malignancy verified a higher malignancy grade when lower MVD and LMD values were obtained (Table 5).

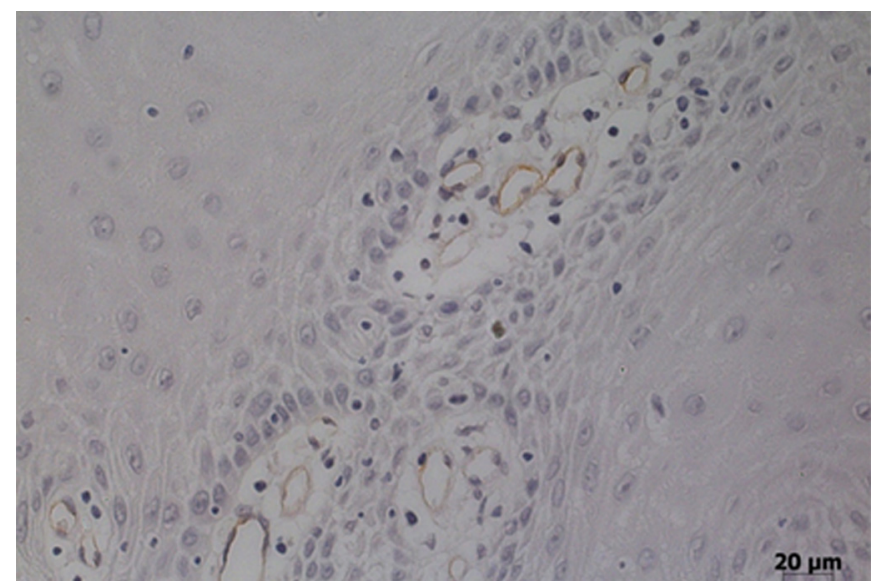

Fig. 2. CD105 labeling blood vessels of tongue squamous cell carcinoma (imunohistochemistry).

To assess the relation between MVD and LMD and tumor severity, the Pearson correlation test was applied. In mouth floor cases, no correlation was detected for highly aggressive $(p=0.602)$ or less aggressive cases $(p=0.469)$. Similarly, no correlation for was

Table 2

Mean \pm standard deviation of MVD, LMD and Ki-67 labeling rate and VEGF and VEGF-C scores.

\begin{tabular}{|c|c|c|c|c|c|c|}
\hline Location & $\begin{array}{l}\text { MVD } \\
\text { CD105 }\end{array}$ & $\begin{array}{l}\text { LMV } \\
\text { D2-40 }\end{array}$ & Classification & VEGF (\% of cases) & VEGF-C (\% of cases) & Ki-67 \\
\hline Tongue & $2.20 \pm 1.07$ & $3.43 \pm 1.59$ & $\begin{array}{l}\text { Absent } \\
\text { Weak } \\
\text { Strong }\end{array}$ & $\begin{array}{r}63.3 \\
30.0 \\
6.6\end{array}$ & $\begin{array}{l}26.66 \\
40 \\
33.33\end{array}$ & $14.0 \pm 13.7$ \\
\hline Floor & $1.65 \pm 1.47$ & $1.87 \pm 1.27$ & $\begin{array}{l}\text { Absent } \\
\text { Weak } \\
\text { Strong }\end{array}$ & $\begin{array}{r}75.7 \\
24.1 \\
3.4\end{array}$ & $\begin{array}{l}21.42 \\
17.85 \\
64.28\end{array}$ & $14.4 \pm 14.1$ \\
\hline
\end{tabular}


Table 3

MVD data (mean \pm standard deviation) and VEGF scores in 59 cases of squamous cell carcinoma.

\begin{tabular}{rlll}
\hline$N$ & VEGF & $\begin{array}{l}\text { MVD } \\
\text { Mean }\end{array}$ & $\begin{array}{l}\text { MVD } \\
\text { Standard deviation }\end{array}$ \\
\hline 40 & Absent & 2.135 & 1.384 \\
16 & Weak & 1.592 & 0.965 \\
3 & Strong & 0.933 & 1.137 \\
\hline
\end{tabular}

determined for highly aggressive $(p=0.815)$ and or less aggressive tumors $(p=0.385)$ in tongue cases.

\section{Discussion}

The morphological grading of malignancy was performed on incisional biopsies in cases of tongue and floor of mouth SCC, according to the system proposed by Bryne et al. [12]. This system analyzes tumor morphology in the more invasive areas of malignant tumors (invasive front), which is frequently different from the central and superficial part of tumors [26]. The exclusion of central and superficial areas in this system is explained by the fact that these areas are likely to be less relevant to tumor behavior [12,26-29].

Although incision biopsies of oral SCC are small and possibly unrepresentative, Bryne et al. [12,27] suggested that the grading system could be used in most cases. In this study, we were able to visualize the invasive front in all the cases selected, thereby permitting the application of the grading system. It was noted that cases considered highly aggressive corresponded to $73.3 \%$ of the neoplasms in the tongue and $96.7 \%$ of those located on the floor of mouth.

In this work, the Kappa test was performed to check the agreement between examiners regarding the histological grading of malignancy. The Kappa test is considered to be a good test of reproducibility, in which values higher than 0.6 are acceptable [30]. According to the results of this study, there was blind agreement between the examiners, thereby increasing the credibility of such assessment.

Alternatives to achieve the reproducibility of the histological grading of malignancy include the omission of the mitosis counts [27], improvements in training programs and calibration among pathologists [28] and simplification of the diagnostic criteria [31]. We opted not to exclude the mitosis counts in order to reproduce the original [12]. Moreover, a greater amount of data were analyzed for each neoplasm, since the material available consisted of incisional biopsies.

In the present study neoplasms located in two anatomic subsites were assessed. These locations are considered the regions of greatest incidence of intraoral SCC, which seem to differ in certain aspects of biological behavior. Zelefsky et al. [32] analyzed cases of tongue and floor of mouth SCC in advanced stages and identified significant differences between these anatomic sub-locations that could affect the therapeutic results in these neoplasms. Moreover, Boldrup et al. [33] verified a regional variation in the expression of tumor protein p63, a member of the p53 family of transcription factors that are involved in the genesis of head and neck SCC. So,

\section{Table 4}

Descriptive statistics (mean \pm standard deviation) of LMD data and their relation with the staining intensity of VEGF-C in 59 cases of squamous cell carcinoma.

\begin{tabular}{llll}
\hline$N$ & VEGF-C & $\begin{array}{l}\text { LMD } \\
\text { Mean }\end{array}$ & $\begin{array}{l}\text { LMD } \\
\text { Standard deviation }\end{array}$ \\
\hline 14 & Absent & 2.550 & 1.713 \\
17 & Weak & 2.306 & 1.432 \\
28 & Strong & 2.933 & 1.710 \\
\hline
\end{tabular}

our group considered opportune to conduct a comparative analysis of tongue and floor of mouth SCC.

The cell proliferation rate is used as a prognostic factor for malignant neoplasm [34]. High Ki-67 indices have been demonstrated in cases of SCC and are correlated with tumor progression and a worse prognosis [15,35]. In this work, Ki-67 labeling showed a wide variation among cases. Although the mean value was higher for mouth floor than for tongue cases, no statistically significant differences between locations were determined. Similar results were reported by Kurokawa et al. [15] and Myoung et al. [35]. The higher proliferation index in the floor tumors seems to be related to the aggressiveness of these cases; however, we were unable to detect significant differences in the proliferation index between these two sites, probably due to the size of the sample analyzed.

Table 5

Mean ( \pm standard deviation) of MVD and LMD data and distribution of cases in each histological degree of malignancy of 59 cases of squamous cell carcinoma.

\begin{tabular}{rlll}
\hline$N$ & Variable & Malignancy & Mean \\
\hline 50 & MVD & High & 1.880 \\
9 & & Low & 2.186 \\
50 & LMD & High & 2.501 \\
9 & & Low & 3.550 \\
\hline
\end{tabular}

Analysis of the results of this study highlighted that CD105 was marked exclusively on the endothelium of new blood vessels, as observed by Kahn and Marks [36] and Minhajat et al. [37] whereas lymphatic vessels were marked by D2-40, a marker that is regarded as selective for lymphatic endothelium [38].

In normal mucosa, Ali [39] observed that lymphatic vessels are rather small and uniformly distributed below the lamina propria, whereas in cases of tongue and floor of mouth SCC the lymphatic vessels stained by D2-40 appeared more elongated and were distributed throughout the stroma, similar to the results obtained herein.

Literature shows conflicting results concerning LMD in SCC behavior. In this study, no relation was detected between cell proliferation and lymphatic microvascular density. Sousa et al. [22] found strong association between LMD and tumor size, however no significant associations between LMD and extent of metastatic disease. Contrary to these results, Inoue et al. [23], Sedivy et al. [40], Sugiura et al. [41] and Watanabe [42] found LMD significantly related with the occurrence of lymph node metastasis. After comparing all the data on the LMD and SCC, it seems reasonable to suggest its influence on tumor aggressiveness. Since the present study was a retrospective study of file cases, the follow-up of patient clinical status was not possible, been a limiting aspect of the analysis.

Following analysis of the entire sample, a relationship between the cell proliferation index and the blood microvascular density (MVD) was determined. Similar results were described by Moul [43] that found higher MVD values in cases with a greater cell proliferation index in SCC in floor of mouth. According to the authors, this fact could be explained by the greater requirement of nutrients and oxygen supplied by the blood vessels, thus a higher proliferation occurs.

The expression of endothelial blood and lymphatic growth factors (VEGF and VEGF-C) by malignant epithelial cells in tongue and floor of mouth SCC was also investigated. Cases with high VEGF labeling presented lower blood microvascular density. These findings suggest that VEGF has minimal influence on the angiogenesis of oral SCC. Some papers have also reported no correlation between vascularization and the expression of VEGF in oral SCC $[44,45]$. In contrast, Inoue et al. [46] and Shang et al. [47] verified that MVD was higher in VEGF-positive than in VEGF-negative cases for esophagus and mouth SCC, respectively. 
Tse et al. [48] affirmed that angiogenesis plays an important role in the prognosis of head and neck SCC. However, they authors presented strong immunohistochemical VEGF labeling, which was considered a predictive factor for worse prognosis in these tumors, an aspect that was not observed in our study.

The dissemination of oral SCC occurs preferentially via the lymphatic system and metastasizes to the regional lymph nodes in $30-40 \%$ of cases [41]. We analyzed the correlation between lymphangiogenesis and the expression of VEGF-C. However, we were unable to determine a clear relationship between them. Miyahara et al. [49] also did not show correlation between LMD and VEGF-C labeling in oral SCC, suggesting that VEGF-C is neither the primary nor the only stimulating factor involved in the progression of oral carcinoma.

However, other researchers have correlated LMD with VEGF-C expression, indicating the importance of its role in lymphangiogenesis in oral SCC [39-41,50]. It seems that cyclooxygenase-2 (COX-2) is involved in VEFG-C pathway of lymphangiogenesis induction, since; both proteins were correlated in lymph node metastasis in oral SCC [50].

The correlation analysis between MVD $\times$ LMD and the histological grading of malignancy showed higher malignancy with lower MVD and LMD values. These data may be interpreted carefully, because the number of less aggressive cases $(n=9)$ was much lower than those that were very aggressive $(n=50)$.

Inconsistency exists among the results from different researchers concerning the role of MVD in squamous cell carcinomas, possibly because of variations in the methodologies. In this research, we chose to use the counting system standardized by Maeda et al. [25]. Besides that, wide variation also occurs in according to the primary antibodies. Among these, we should highlight factor VIII-related anti-Von Willebrand, CD31, CD34 and anti-endoglin (CD105), used to evaluate tumor vascularization [51,52]. In this study, CD105 immunohistochemical labeling was used, and effectively stained neoformed blood vessels, thereby permitting adequate MVD quantification.

While no difference was detected between MVD in tongue and floor of mouth lesions, LMD was significantly different between these regions and was greater in tongue cases. The difference obtained for lymphatic vascular density seems to be related to the anatomic location of the tumor and this could be an important factor for the occurrence of lymph node metastasis. It is known that the risk of metastasis for different-sized lesions differs according to the anatomic location; for example, there are more metastases from tumors present at the base of the tongue, where there is a rich vascular and lymphatic network, when compared to similar sized lesions located on the oral tongue [53].

This study demonstrated that the expression of blood and lymphatic vascular growth factors and lymphatic microvascular density do not present correlation with morphological grading of malignancy nor with cell proliferation in SCC, a presumptive prognostic factor for this neoplasm. However, blood microvascular density was shown to be greater in cases with a higher proliferation rate, demonstrating a relation with tumor prognosis.

\section{Conclusions}

Floor of mouth squamous cell carcinoma cases was morphologically more aggressive than tongue cases; however, in tongue carcinomas, a greater quantity of lymphatic vessels represent potential routes for locoregional cell dissemination of the neoplastic cells, independent of the histological grading. Blood vascularization presents a correlation with cell proliferation in intraoral squamous cell carcinoma and could assist in the prognostic evaluation of this neoplasm.

\section{Conflict of interest}

The authors declare that they have no conflict of interest.

\section{Acknowledgements}

The authors thank FAPESP (São Paulo State Research Foundation) for the scholarship (PROC 10/20127-7).

\section{References}

[1] Warnakulasuriya S. Global epidemiology of oral and oropharyngeal cancer. Oral Oncol 2009;45:309-16.

[2] Pulte D, Brenner H. Changes in survival in head and neck cancers in the late 20th and early 21st century: a period analysis. Oncologist 2010:15:994-1001.

[3] Massano J, Regateiro FS, Januario G, Ferreira A. Oral squamous cell carcinoma: review of prognostic and predictive factors. Oral Surg Oral Med Oral Pathol Oral Radiol Endod 2006;102:67-76.

[4] Parkin DM, Pisani P, Ferlay J. Estimates of the worldwide incidence of eighteen major cancers in 1985. Int J Cancer 1993;54:594-606.

[5] Barnes L, Eveson JW, Reichart P, Sidranski D. World Health Organization classification of tumours. Pathological and genetics of head and neck tumours. Lion: IARC Press; 2005. p. 168-75.

[6] Mashberg A, Samit A. Early diagnosis of asymptomatic oral and oropharyngeal squamous cancers. CA Cancer J Clin 1995;45:328-51.

[7] Fedele S. Diagnostic aids in the screening of oral cancer. Head Neck Oncol 2009; $1: 5$.

[8] Kademani D, Bell RB, Bagheri S, Holmgren E, Dierks E, Potter B, et al. Prognostic factors in intraoral squamous cell carcinoma: the influence of histologic grade. J Oral Maxillofac Surg 2005;63:1599-605

[9] Imai Y, Sasaki T, Fujibayashi T. Volume-corrected mitotic index as a prognostic factor in oral squamous cell carcinomas. Oral Oncol 2001;37:72-4.

[10] Broders AC. Carcinoma. Grading and practical application. Arch Pathol 1926;2:376-81.

[11] Anneroth G, Batsakis J, Luna M. Review of the literature and a recommended system of malignancy grading inoral squamous cell carcinomas. Scand J Dent Res 1987;95:229-49.

[12] Bryne M, Koppang HS, Lilleng R, Stene T, Bang G, Dabelsteen E. New malignancy grading is a better prognostic indicator than Broder's grading in oral squamous cell carcinomas. J Oral Pathol Med 1989;18:432-7.

[13] Jepsen SA, Closmann JJ. The insidious nature and presentation of oral squamous cell carcinoma in the low-risk population. Gen Dent 2008;56:78-82.

[14] Mehrotra R, Gupta A, Singh M, Ibrahim R. Application of cytology and molecular biology in diagnosing premalignant or malignant oral lesions. Mol Cancer 2006;5:11.

[15] Kurokawa H, Zhang M, Matsumoto S, Yamashita Y, Tanaka T, Tomoyose T, et al. The relationship of the histologic grade at the deep invasive front and the expression of Ki-67 antigen and p53 protein in oral squamous cell carcinoma. J Oral Pathol Med 2005;34:602-7.

[16] Tumuluri V, Thomas GA, Fraser IS. Analysis of the Ki-67 antigen at the invasive tumour front of human oral squamous cell carcinoma. J Oral Pathol Med 2002;31:598-604.

[17] Matter A. Tumor angiogenesis as a therapeutic target. Drug Discov Today 2001;6:1005-24.

[18] Stacker SA, Achen MG, Jussila L, Baldwin ME, Alitalo K. Lymphangiogenesis and cancer metastasis. Nat Rev Cancer 2002;2:573-83.

[19] Franchi A, Gallo O, Massi D, Baroni G, Santucci M. Tumor lymphangiogenesis in head and neck squamous cell carcinoma: a morphometric study with clinical correlations. Cancer 2004;101:973-8.

[20] Dadras SS, Lange-Asschenfeldt B, Velasco P, Nguyen L, Vora A, Muzikansky A, et al. Tumor lymphangiogenesis predicts melanoma metastasis to sentinel lymph nodes. Mod Pathol 2005;18:1232-42.

[21] Gombos Z, Xu X, Chu CS, Zhang PJ, Acs G. Peritumoral lymphatic vessel density and vascular endothelial growth factor $\mathrm{C}$ expression in early-stage squamous cell carcinoma of the uterine cervix. Clin Cancer Res 2005;11:8364-71.

[22] Sousa SF, Gleber-Netto FO, Oliveira-Neto HH, Batista AC, Nogueira Guimarães Abreu MH, de Aguiar MC. Lymphangiogenesis and podoplanin expression in oral squamous cell carcinoma and the associated lymph nodes. Appl Immunohistochem Mol Morphol 2012;20:588-94.

[23] Inoue M, Roan CH, Abe T, Buery RR, Nagatsuka H, Katase N, et al. Localization and characterization of lymphatic vessels in oral and cervical squamous cell carcinoma. Exp Ther Med 2011;2:793-7.

[24] Soini Y, Puhakka A, Kahlos K, Säily M, Pääkkö P, Koistinen P, et al. Endothelial nitric oxide synthase is strongly expressed in malignant mesothelioma but does not associate with vascular density or the expression of VEGF, FLK1 or FLT1. Histopathology 2001;39:179-86.

[25] Maeda K, Chung YS, Takatsuka S, Ogawa Y, Onoda N, Sawada T, et al. Tumour angiogenesis and tumor cell proliferation as prognostic indicators in gastric carcinoma. Br J Cancer 1995;72:319-23.

[26] Bryne M. Is the invasive front of an oral carcinoma the most important area for prognostication? Oral Dis 1998;4:70-7. 
[27] Bryne M, Koppang HS, Lilleng R, Kjaerheim A. Malignancy grading of the deep invasive margins of oral squamous cell carcinomas has high prognostic value. J Pathol 1992;166:375-81.

[28] Bryne M, Bryne M, Koppang HS, Lilleng R, Stene T. The invasive front of carcinomas. The most important part for tumour prognostication? A review. Anticancer Res 1998;18:4757-64.

[29] Bryne M. Prognostic value of various molecular and cellular features in oral squamous cell carcinomas: a review. J Oral Pathol Med 1991;20:413-20.

[30] Fleming KA. Evidence-based pathology. J Pathol 1996;179:127-8.

[31] Woolgar JA, Scott J, Vaughan ED, Brown JS, West CR, Rogers S. Survival, metastasis and recurrence of oral cancer in relation to pathological features. Ann $\mathrm{R}$ Coll Surg Engl 1995;77:325-31.

[32] Zelefsky MJ, Harrison LB, Fass DE, Armstrong JG, Shah JP, Strong EW. Postoperative radiation therapy for squamous cell carcinomas of the oral cavity and oropharynx: impact of therapy on patients with positive surgical margins. Int J Radiat Oncol Biol Phys 1993;25:17-21.

[33] Boldrup L, Coates PJ, Laurell G, Nylander K. Differences in p63 expression in SCCHN tumours of different sub-sites within the oral cavity. Oral Oncol 2011;47:861-5

[34] Liu M, Lawson G, Delos M, Jamart J, Ide C, Coche E, et al. Predictive value of the fraction of cancer cells immunolabeled for proliferating cell nuclear antigen or Ki67 in biopsies of head and neck carcinomas to identify lymph node metastasis: comparison with clinical and radiologic examinations. Head Neck $2003 ; 25: 280-8$.

[35] Myoung H, Kim MJ, Lee JH, Paeng JY Yun PY Correlation of proliferative markers [Ki-67 and PCNA] with survival and lymph node metastasis in oral squamous cell carcinoma: a clinical and histopathological analysis of 113 patients. Int J Oral Maxillofac Surg 2006;35:1005-10.

[36] Kahn HJ, Marks A. A new monoclonal antibody, D2-40 for detection of lymphatic invasion in primary tumours. Lab Invest 2002;82:1255-7.

[37] Minhajat R, Mori D, Yamasaki F, Sugita Y, Satoh T, Tokunaga O. Endoglin [CD105] expression in angiogenesis of colon cancer: analysis using tissue microarrays and comparison with other endothelial markers. Virchows Arch 2006;448:127-34.

[38] Ohno F, Nakanishi H, Abe A, Seki Y, Kinoshita A. Hasegawa Y, et al. Regional difference in intratumoral lymphangiogenesis of oral squamous cell carcinomas evaluated by immunohistochemistry using D2-40 and podoplanin antibody: an analysis in comparison with angiogenesis. J Oral Pathol Med 2007;36: 281-9.

[39] Ali MA. Lymphatic microvessel density and the expression of lynphangiogenic factors in oral squamous cell carcinoma. Med Princ Pract 2008;17:486-92.

[40] Sedivy R, Beck-Mannagetta J, Haverkampf C, Battistutti W, Honigschnab $\mathrm{S}$. Expression of vascular endothelial growth factor-C correlates with the lymphatic microvessel density and the nodal status in oral squamous cell cancer. J Oral Pathol Med 2003;32:455-60.

[41] Sugiura T, Inoue Y, Matsuki R, Ishii K, Takahashi M, Abe M, et al. VEGF-C and VEGF-D expression is correlated with lymphatic vessel density and lymph node metastasis in oral squamous cell carcinoma: implications for use as a prognostic marker. Int J Oncol 2009;34:673-80.

[42] Watanabe S, Kato M, Kotani I, Ryoke K, Hayashi K. Lymphatic vessel density and vascular endothelialgrowth factor expression in squamous cell carcinomas of lip and oral cavity: a clinicopathological analysis with immunohistochemistry using antibodies to D2-40, VEGF-C and VEGF-D. Yonago Acta Med 2013;56:29-37

[43] Moul JW. Angiogenesis, p53, bcl2 and Ki-67 in the progression of prostate cancer after radical prostatectomy. Eur Urol 1999;35:399-407.

[44] Artese L, Rubini C, Ferrero G, Fioroni M, Santinelli A, Piatelli A. Microvessel density [MVD] and vascular endothelial growth factor expression [VEGF] in human oral squamous cell carcinoma. Anticancer Res 2001;21:689-95.

[45] E.L-Gazzar R, Macluskey M, Williams H, Ogden GR. Vascularity and expression of vascular endothelial growth factor in oral squamous cell carcinoma, resection margins, and nodal metastases. Br J Oral Maxillofac Surg 2006;44:193-7.

[46] Inoue K, Ozeki Y, Suganuma T, Sugiura Y, Tanaka S. Vascular endothelial growth factor expression in primary esophageal squamous cell carcinoma. Association with angiogenesis and Tumor progression. Cancer 1997;79:206-13.

[47] Shang ZJ, Li JR, Li ZB. Circulating levels of vascular endothelial growth factor in patients with oral squamous cell carcinoma. Int J Oral Maxillofac Surg 2002;31:495-8.

[48] Tse GM, Chan AW, Yu KH, King AD, Wong KT, Chen GG, et al. Strong immunohistochemical expression of vascular endothelial growth factor predicts overall survival in head and neck squamous cell carcinoma. Ann Surg Oncol 2007; 14:3558-65.

[49] Miyahara M, Tanuma J, Sugihara K, Semba I. Tumor lymphangiogenesis correlates with lymph node metastasis and clinicopathologic parameters in ora squamous cell carcinoma. Cancer 2007:110:1287-94.

[50] Kono M, Watanabe M, Abukawa H, Hasegawa O, Satomi T, Chikazu D. Cyclooxygenase-2 expression is associated with vascular endothelial growth factor $C$ expression and lymph node metastasis in oral squamous cell carcinoma. J Oral Maxillofac Surg 2013:71:1694-702.

[51] Kyzas PA, Stefanou D, Batistatou A, Agnantis NJ. Prognostic significance of VEGF immunohistochemical expression and tumor angiogenesis in head and neck squamous cell carcinoma. J Cancer Res Clin Oncol 2005;131:624-30.

[52] Duff SE, Li C, Garland JM, Kumar S. CD-105 is important for angiogenesis: evidence and potential applications. FASEB J 2003;17:984-92

[53] Genden EM, Ferlito A, Bradley PJ, Rinaldo A, Scully C. Neck disease and distant metastases. Oral Oncol 2003:39:207-12. 